\title{
Finanças comportamentais: análise do comportamento humano sob perspectiva de risco
}

\author{
Leonardo de Paula* \\ Karine Lúcia Foppa** \\ Samara Carla Dellazzari*** \\ Cássia Heloisa Ternus****
}

\section{Resumo}

A ideia de que os investidores tomam decisões racionais deixou de ser amplamente aceita a partir dos anos 1960. Estudos desenvolvidos desde então apontam que os indivíduos apresentam racionalidade limitada quando expostos ao processo de tomada de decisão. $\mathrm{O}$ objetivo deste trabalho consiste em analisar se há diferenças significativas nas escolhas envolvendo risco por parte de acadêmicos da área de negócios, e se há distinção quando segmentada a amostra por gênero, perfil de investimento e período da graduação. O estudo fez uso das finanças comportamentais, optando-se por replicar o questionário do trabalho de Kahneman e Tversky (1979). Os dados foram coletados por meio de questionários, utilizouse estatística descritiva para a análise e o teste qui-quadrado para verificação da significância estatística. Os resultados revelaram maior presença do público feminino e do perfil conservador em escolhas mais avessas ao risco, e em decisões mais arriscadas o público masculino e perfil arrojado tiveram resultados mais expressivos. Quanto ao período da graduação, os resultados não se mostraram estatisticamente significativos.

Palavras chaves: finanças comportamentais; escolhas; área de negócios.

\section{Behavioral finance: analysis of human behavior from risk perspectives}

\begin{abstract}
The idea that investors make rational decisions are no widely accepted since the 1960s. Studies developed since then point out that individuals have limited rationality when exposed to the decision-making process. The objective of this work is to analyze if there are differences in the choices by academics in the business area, and if there is a distinction when segmenting the sample by gender, investment profile and graduation period. The study made use of behavioral finance, opting to replicate the questionnaire of the work of Kahneman and Tversky (1979). The data were collected through questionnaires, descriptive statistics as a tool for the analysis and the chi-square test to verify statistical significance. The results revealed a greater presence of the female public and the conservative profile in more riskaverse choices, and in more risky decisions the male audience and bold profile had more expressive results. As for the graduation period, the results were not statistically significant.
\end{abstract}

Keyword: behavioral finance; choices; business area.

\section{Classificação JEL: G41; D91.}

* Bacharel em Economia pela Universidade Comunitária da Região de Chapecó (UNOCHAPECO). E-mail: leonardo.paula@unochapeco.edu.br

** Bacharel em Economia pela Universidade Comunitária da Região de Chapecó (UNOCHAPECO). E-mail: karine.f@unochapeco.edu.br

*** Bacharel em Economia pela Universidade Comunitária da Região de Chapecó (UNOCHAPECO). E-mail: samara.dellazzari@unochapeco.edu.br

**** Professora do Curso de Ciências Econômicas da Universidade Comunitária da Região de Chapecó (UNOCHAPECO). E-mail: cassia_ternus@ unochapeco.edu.br 


\section{Introdução}

Fatores como previsões políticas e econômicas, projeções de ganhos e perdas, aspectos emocionais e até mesmo expectativas, podem influenciar decisões financeiras em situações envolvendo risco. Contudo, apesar desses aspectos, o nível de conhecimento é um importante fator na composição das escolhas.

Segundo Anache (2008), as finanças comportamentais estão em destaque na economia devido sua importância para a explicação das escolhas individuais. O presente artigo utilizou como base esse tema, em virtude da capacidade que este campo de estudo demonstrou para a explicação das escolhas dos agentes com relação às finanças.

Mesmo dotado de informações, os indivíduos não agem de maneira racional em todas as escolhas. De modo geral, os investidores buscam maximizar seus resultados enquanto reduzem os riscos, e com o passar dos anos de estudo e de experiência adquirida, as escolhas podem ser influenciadas por estes fatores. Deste modo, este trabalho buscou responder, a seguinte problemática: o gênero, o posicionamento frente a investimentos e os anos de estudos podem influenciar as preferências de estudantes do ensino superior em decisões envolvendo risco?

Neste sentido, os dados deste estudo referem-se aos acadêmicos dos cursos de Administração, Ciências Contábeis e Ciências Econômicas, de uma instituição de ensino superior e sua escolha se justifica por integrarem a área de negócios, na qual espera-se que os estudantes sejam preparados para lidar com situações impostas pelo mercado financeiro, o que pode impactar sua percepção perante situações de risco. Para a análise, os cursos são examinados como um todo sem distinção, tendo o respaldo da estatística descritiva e de testes qui-quadrado para responder aos objetivos propostos.

O objetivo desta pesquisa consiste em analisar se há diferenças significativas nas escolhas envolvendo risco de acadêmicos da área de negócios, verificando, ainda, se há distinção quando segmentada a amostra por gênero, perfil de investimento (autodeclarado) e período da graduação. Para isso, as análises pautam-se em três pilares, primeiramente é analisado se o gênero interfere nas decisões envolvendo risco. Após, compara-se o posicionamento frente a investimentos com as escolhas dos indivíduos, a fim de saber se existe uma relação entre as variáveis. E, por fim, verificam-se os anos de estudo exercem influência nas escolhas dos acadêmicos da área de negócios perante situações que envolvem riscos. 
Assim sendo, o presente estudo encontra-se dividido em cinco seções. Nesta primeira seção, apresenta-se o objetivo principal; na segunda seção discutem-se as finanças comportamentais sob perspectiva teórica; na terceira seção realizam-se os procedimentos metodológicos; na quarta seção, apresentam-se os resultados da pesquisa realizada; e, por fim na quinta seção faz-se as considerações finais.

\section{Finanças comportamentais}

Os estudos tradicionais em finanças evoluíram ao longo do século XIX, construídos a partir de uma abordagem microeconômica neoclássica. Segundo as teses dessa área, o agente toma suas decisões com base nas informações que estão disponíveis a ele no momento e nas suas expectativas racionais, buscando sempre as melhores combinações de bens e serviços capazes de maximizar sua satisfação (PINDYCK; RUBINFELD, 2006).

Halfeld e Torres (2001) argumentam que nesta corrente teórica, os indivíduos atuantes em mercados financeiros utilizam corretamente suas crenças e recebem novas informações para melhor atuarem diante das escolhas.

De acordo com Kahneman e Tversky (1979), a primeira teoria utilizada para explicar como os indivíduos se posicionavam, foi a utilidade esperada (TUE). De acordo com a qual, os indivíduos sempre dispunham dos melhores instrumentos para a tomada de decisões, bem como das melhores informações, sendo que as escolhas vistas como "erradas", eram classificadas como erros aleatórios. Usualmente, tal teoria foi aceita como um modelo normativo de escolha racional e como um modelo descritivo de comportamento econômico, onde supõe-se que todas as pessoas pensam e agem racionalmente, na maior parte do tempo.

A fórmula da TUE, apresenta a utilidade esperada, representada por $\mathrm{U}=(\mathrm{X} 1, \mathrm{Pi} ; \ldots$; $\mathrm{Xn}, \mathrm{Pn})$, onde $(\mathrm{X})$ corresponde valor do prospecto, multiplicado por $(\mathrm{P})$ que corresponde a probabilidade. Deste modo, cada decisão pode ser mensurada antes de ser escolhida, por meio do cálculo do valor que será obtido. Seguindo está teoria o indivíduo, sempre escolheria pela melhor opção de acordo com a utilidade esperada; no entanto, isso não é o suficiente para explicar as escolhas segundo Kahneman e Tversky (1979).

A partir da década de 1970, alguns fatores incentivaram os estudos em finanças comportamentais, quando o modelo moderno de finanças utilizado para explicar o comportamento do mercado começou a apresentar falhas em estudos empíricos. (HALFELD; TORRES, 2001). Nesse sentido, Varian (2012) afirma que os estudos baseados 
no modelo do agente racional são incompletos e, em muitos casos, não conseguem explicar alguns fenômenos financeiros.

Diante das falhas que deram início aos estudos em finanças comportamentais, observaram-se algumas anomalias do mercado financeiro, como a autoconfiança, o otimismo e pessimismo, e reações perante às novidades do mercado, que, aliadas a outros conceitos como a aversão à perda, tornaram as finanças comportamentais um dos assuntos mais polêmicos do ramo das finanças (HALFELD; TORRES, 2001). Além disso, outros fatores são considerados fundamentais para que se possa entender o direcionamento das escolhas. Dentre eles, o principal é o chamado efeito manada, segundo o qual, quando o mercado está desregulado, coexistindo com a falta de informações, os investidores tomam suas decisões de acordo com os demais agentes. Fazendo com que não haja estratégias de alocação (FRANCESCHINI, 2015).

No mesmo sentido, estudos recentes na área da economia buscam algumas formas de explicar as escolhas dos indivíduos. Esses estudos econômicos vêm acompanhados por pesquisas também de outras áreas, como a psicologia e a sociologia, que visam entender o comportamento e as escolhas desses agentes, por meio de previsões (VARIAN, 2012).

Desses estudos surge a economia comportamental, baseada no pressuposto de racionalidade limitada, buscando entender como os agentes se comportam, sabendo que eles não seguem os padrões lógicos o tempo todo (READ, 2015). Seguindo essa linha de raciocínio, Ferreira (2015) argumenta que esses estudos utilizam ferramentas mais sofisticadas, que captam o posicionamento das pessoas frente aos acontecimentos do mercado, levando em consideração suas expectativas e experiências vividas.

Para explicar as finanças comportamentais, um dos principais trabalhos utilizados é o desenvolvido por Kahneman e Tversky (1979), no qual desenvolve-se a teoria do prospecto. Está teoria é um modelo alternativo sobre as escolhas dos indivíduos e é utilizada como ferramenta de descrição do processo de tomada de decisão (KIMURA; BASSO, KRAUTER, 2006).

Segundo essa teoria, no processo decisório os ganhos e as perdas possuem pesos diferentes, e o indivíduo mesmo em posse das informações de mercado, não age de maneira racional o tempo todo (KAHNEMAN; TVERSKY, 1979).

Kahneman e Tversky (1979), descrevem três efeitos com relação aos prospectos. Tem-se o efeito certeza, onde os indivíduos são confrontados com alternativas de ganhos, de modo a escolher a opção com maior probabilidade de ganho, independentemente do valor que a mesma aufere, posicionando-se de maneira avessa ao risco. Existe o efeito reflexão, 
onde os indivíduos são colocados frente duas situações, sendo uma de ganho e a outra de perda, deste modo espera-se que o indivíduo se posicione de modo avesso ao risco para situações de ganho, e propenso para situações de perdas, afim de minimizar o prejuízo. E, também, existe o efeito isolamento, no qual o indivíduo antes de fazer a escolha recebe uma bonificação, sendo colocado frente duas situações - uma de ganho e a outra de perda -, esperando-se que ele desconsidere tal bônus, sendo avesso ao risco para ganhos e propenso para perdas.

Kahneman e Tversky (1982), salientam que as finanças comportamentais desafiam o paradigma da hipótese de mercados eficientes e que as decisões financeiras podem sofrer intervenções por processos mentais. Lima (2003) complementa que esta abordagem, investiga o comportamento dos investidores e como os mesmos reagem de acordo com as informações que possuem para a tomada de decisões perante os investimentos. Nesse sentido, Thaler e Barberis (2003) a estabelecem como o estudo da mente, afirmando que para solucionar um problema financeiro, muitas vezes será necessário considerar que os agentes não se comportam de maneira racional.

O posicionamento contrário as novidades, propensão a riscos, efeito certeza e isolamento são subfatores que facilitam a compreensão das tomadas de decisões dos investidores (HALFELD; TORRES, 2001). Juntamente a esses fatores, o conceito de aversão a perdas auxilia a compreensão de determinadas escolhas, segundo Milanez (2003). Este relaciona-se às diferentes maneiras de como uma situação é apresentada e às múltiplas reações que pode produzir.

Ainda sobre a aversão a perdas, Halfeld e Torres (2001) reconhecem que as pessoas sentem muito mais o sofrimento pela perda do que o bem-estar proporcionado por um ganho. Neste ponto de vista, Melo e Silva (2010) argumentam que o ser humano se arrisca para evitar as perdas e, com relação aos ganhos, ocorre o oposto, pois é preferível o rendimento julgado como certo, do que o risco para se obterem novos ganhos. Este conceito é um dos pilares das finanças comportamentais.

Essa sensibilidade que os indivíduos possuem frente a situações de ganhos e perdas, é melhor abordada pela função valor. Esta função mostra o que o indivíduo é mais sensível às perdas, onde a linha do gráfico é mais acentuada, e menos sensível aos ganhos onde a linha do encontra-se suavizada, conforme exposta na Figura 1.

Para Yoshinaga et al. (2008), a área de pesquisa entorno das finanças comportamentais é recente, porém muito promissora. Dentre as motivações fundamentais para o progresso deste campo estão os estudos empíricos, que questionam os modelos 
tradicionais e a vasta coleção de resultados que se basearam em explorações comportamentais.

Seguindo esta linha de pesquisa, alguns trabalhos replicaram os experimentos de Kahneman e Tversky (1979), uma vez que este deu origem aos questionamentos da área. Kimura, Basso e Krauter (2006) replicaram este estudo para uma amostra brasileira, e identificaram os mesmos viéses encontrados pelos autores originais.

Figura 1: Função Valor.

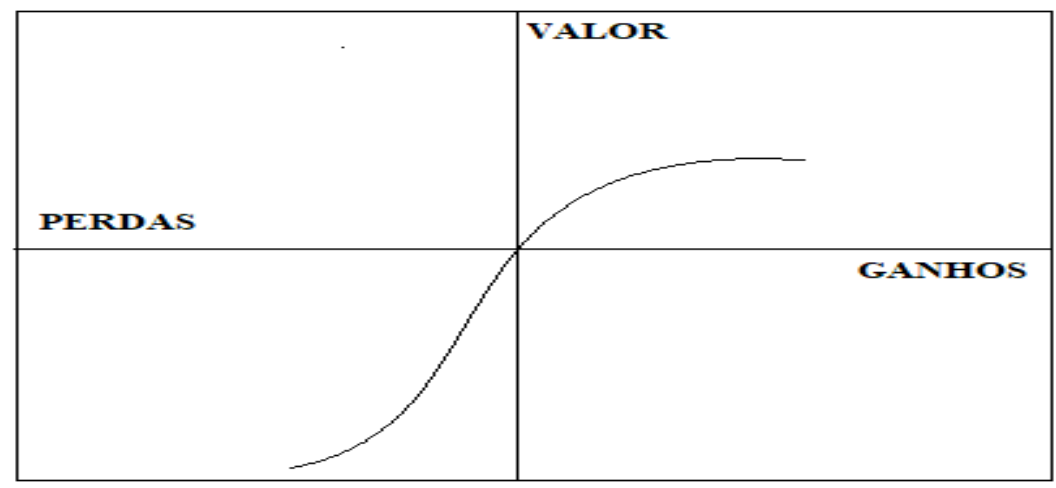

Fonte: Elaborado com base em Kahneman e Tversky (1979).

No mesmo sentido, Cavallaro et al. (2015) buscaram verificar se diferentes cursos, juntamente da idade, gênero e renda dos indivíduos impactam nas escolhas envolvendo riscos no mercado financeiro. Foi observada uma amostra de 195 alunos de oito diferentes cursos de graduação, de modo que se constatou o gênero como uma variável determinante nas escolhas dos indivíduos, sendo o feminino o mais avesso ao risco. As demais variáveis não exerceram influência tão expressiva.

Com relação a análise de gênero, Barros e Felipe (2015) utilizaram os estudos de Kahneman e Tversky (1979) para identificar quais viéses psicológicos interferem em decisões financeiras. Por meio de dados primários e de estatística descritiva, os autores evidenciaram a existência de três efeitos no processo decisório, efeito certeza, reflexão e isolamento, e que de um modo geral o público feminino é mais avesso ao risco quando comparado ao masculino.

Oliveira e Krauter (2015) investigaram se as pessoas, atuantes no mercado de trabalho e com nível superior, têm uma percepção de risco diferente de pessoas que ainda não trabalham, mas que estão em processo de formação. Os resultados comprovaram que os agentes não são racionais, além disso, que a qualificação e a experiência profissional não exercem influência na tomada de decisão dos agentes. 
De maneira similar, Barbosa et al. (2017) analisaram a relação entre o perfil dos acadêmicos e profissionais da área de atuária com aos aspectos comportamentais. As informações foram coletadas por meio de questionários, onde os estudantes demonstraram ser sensíveis e avessos aos riscos em relação aos ganhos; enquanto, os profissionais apresentaram preferência por alternativas que remetem a ganho maior.

Nesta mesma linha de pesquisa Soares e Barbedo (2013), analisaram como os indivíduos se posicionavam no mercado financeiro, uma vez que dispunham de diferentes informações assim como fontes. Comparando profissionais em atuação com acadêmicos, verificou-se que a formação possui peso nas decisões fazendo, com que os profissionais sejam mais propensos ao risco em função de ganhos maiores.

Do mesmo modo, Haubert et al. (2014) elaboraram um estudo sobre o comportamento financeiro para estudantes de pós-graduação com base nas finanças comportamentais. A coleta de dados, ocorreu por meio de questionários, de modo que os resultados encontrados mostraram que os perfis estabelecidos para a amostragem foram o conservador e moderado.

Barros e Felipe (2015) utilizaram as finanças comportamentais e os estudos de Kahneman e Tversky (1979) para identificar quais viéses psicológicos interferem em decisões financeiras. Por meio de dados primários e de estatística descritiva, os autores evidenciaram a existência dos três efeitos no processo decisório, efeito certeza, reflexão e isolamento. E, que de um modo geral, o público feminino é mais avesso ao risco quando comparado ao masculino. Também, fazendo uso das finanças comportamentais, Haubert, Lima e Herling (2012) se propuseram a mostrar como estudantes de pós-graduação se comportavam em relação aos investimentos financeiros, com o uso de estatística descritiva e econometria para apurar dados primários. De um modo geral, os resultados obtidos mostraram um público de perfil conservador e que tomavam as decisões seguindo o efeito reflexão da teoria do prospecto.

\section{Procedimentos metodológicos}

A amostra é composta de dados primários, que foram coletados por meio de questionários. Este trabalho desenvolveu-se pelo olhar quantitativo e descritivo, com o respaldo da teoria econômica comportamental, para a explicação dos objetivos propostos. 
Como público alvo, optou-se por acadêmicos dos cursos de Administração, Ciências Contábeis e Ciências Econômicas de uma Instituição de Ensino Superior da cidade de Chapecó - SC. Os cursos foram escolhidos por integrarem a área de negócios, de maneira que se espera que os acadêmicos desta área sejam preparados para lidar com diferentes situações impostas pelo mercado financeiro.

A coleta de dados foi realizada com a aplicação de um questionário composto por três seções. A primeira seção aborda as características pessoais dos entrevistados. A segunda destaca o posicionamento dos acadêmicos em situações que envolvem investimentos financeiros, onde os indivíduos autodefinem seu perfil como conservadores, moderados ou arrojados. A terceira e última faz menção a teoria do prospecto, colocando o indivíduo frente a situações envolvendo risco.

$\mathrm{O}$ instrumento de coleta de dados deste artigo, embasou-se em dois questionários aplicados em estudos anteriores. O primeiro, diz respeito a um estudo proposto por Lencini e Andrade (2016), para investidores de instituições financeiras de Porto Alegre (RS). Com esse questionário, os pesquisadores buscaram estabelecer o perfil do investidor através de seu posicionamento em situações ligadas a investimentos. Desse questionário foram utilizadas as questões ligadas às características pessoais e ao posicionamento frente a investimentos. Essas compõem a primeira e a segunda seções do instrumento de coleta desta pesquisa.

O segundo questionário foi elaborado por Kahneman e Tversky (1979) e aplicado com professores e acadêmicos. O objetivo dos pesquisadores era mostrar como os indivíduos agiam frente a situações envolvendo risco, supondo que suas escolhas violavam a teoria da utilidade esperada, em favor dos efeitos certeza, reflexão e isolamento.

Após a aplicação do pré-teste, ${ }^{1}$ foram realizados os ajustes necessários no instrumento de coleta de dados. Os questionários foram aplicados ${ }^{2}$ com os acadêmicos de todos os períodos do curso de Administração, Ciências Contábeis e Ciências Econômicas, embora não tenha havido distinção entre os cursos para análise dos dados.

A análise foi desenvolvida a partir de estatística descritiva, com o uso de frequências das respostas, e o nível de significância foi verificado com o teste qui-quadrado. Este teste permite comparar a dispersão entre duas ou mais variáveis, e avaliar a associação entre as mesmas, apontando a significância estatística existente. Primeiramente, foram confrontadas

\footnotetext{
${ }^{1}$ O pré-teste deste instrumento foi realizado na primeira quinzena de agosto de 2018 , com uma amostra de 22 indivíduos.

${ }^{2}$ Os questionários foram aplicados entre os dias $17 / 10$ e 05/11.
} 
as questões relacionadas a teoria do prospecto com características pessoais, representadas pelo gênero dos acadêmicos. O intuito foi de verificar se haviam diferenças significativas nas escolhas frente a risco entre homens e mulheres.

Posteriormente, as respostas dos acadêmicos relacionadas ao posicionamento frente ao risco foram comparadas com a auto declaração dos mesmos, referente ao seu perfil de investimento. Nessa questão, os respondentes optavam pela alternativa que melhor representasse seu perfil: Conservador, Moderado ou Arrojado. Espera-se que quanto mais conservador seja o perfil da amostra, maior tende a ser a aversão ao risco. De modo similar, quanto mais arrojado for o perfil, maior a propensão ao risco.

Por fim, com a intenção de analisar se haveriam diferenças significativas nas escolhas dos acadêmicos a partir da exposição ao ensino superior em cursos relacionados à área de negócios, confrontou-se as questões da Teoria do Prospecto com o período de graduação dos alunos. Para evitar distorções, uma vez que nem todos os cursos possuem acadêmicos em todos os períodos, esta variável foi categorizada por quartil.

Como um todo a amostra é composta por 374 respondentes, conforme a Tabela 1. Para as variáveis gênero e perfil de investidor, houve um percentual de $100 \%$ de respondentes. Contudo, ao ser analisado o período de graduação constatou-se que nem todos os indivíduos responderam, de modo que se obteve um percentual de 93,05\% de respostas para a categoria, com um total de 348 informações.

Tabela 1: Composição da amostra por grupos de análise

\begin{tabular}{|c|c|c|c|c|c|c|c|c|c|}
\hline \multirow[t]{2}{*}{ GERAL } & \multicolumn{2}{|c|}{ GÊNERO } & \multicolumn{3}{|c|}{ PERFIL } & \multicolumn{4}{|c|}{ PERÍODO DA GRADUAÇÃO } \\
\hline & MASCULINO & FEMININO & CONSERVADOR & MODERADO & ARROJADO & 1 & 2 & 3 & 4 \\
\hline 374 & 185 & 189 & 127 & 224 & 23 & 138 & 64 & 70 & 76 \\
\hline $100 \%$ & $49,46 \%$ & $50,54 \%$ & $33,95 \%$ & $59,89 \%$ & $6,16 \%$ & $39,65 \%$ & $18,39 \%$ & $20,11 \%$ & $21,85 \%$ \\
\hline
\end{tabular}

O trabalho original de Kahneman e Tversky (1979) utilizou 99\% como nível de significância estatística. Contudo, como os autores não realizaram a análise por grupos, optou-se por flexibilizar o nível de significância da pesquisa e representar, também, os resultados com 95\% de significância. Deste modo, as questões que apresentaram 0,01 de confiança estatística estão representadas com (**), enquanto as que representam 0,05 de confiança estatística estão indicadas com (*). 
A próxima seção contém os resultados obtidos e analisados com base no trabalho de Kahneman e Tversky (1979), o qual foi realizado dividindo as questões em pares e agrupadas dentro dos efeitos certeza, reflexão e isolamento.

\section{Resultados}

A análise embasou-se no trabalho feito por Kahneman e Tversky (1979), onde os resultados foram observados seguindo os pressupostos dos efeitos certeza, reflexão e isolamento. Em cada um dos efeitos, as questões são analisadas em pares, de modo que na segunda questão são expostos prospectos inversos aos disponíveis na primeira questão. $\mathrm{O}$ intuito desta metodologia foi verificar se as respostas seguiam os padrões impostos para cada um dos efeitos, para ser estabelecida a situação de respeito ou violação dos pressupostos segmentados.

\subsection{Efeito certeza}

Ao analisar o efeito certeza, é possível verificar que as escolhas dos agentes podem violar o princípio da utilidade esperada, implicando na violação do axioma da substituição/transitividade, ou seja, os indivíduos tendem a dar maior peso às possibilidades que têm maior probabilidade de acontecer (MACEDO JUNIOR, 2003).

As tabelas apresentam os resultados por pares de respostas, segmentados por variáveis de análise. Os valores indicam a porcentagem de escolha em cada prospecto. $\mathrm{O}$ número de respondentes de cada problema é indicado por $N$. Na tabela 2 são expostos os resultados, seguido pela análise desenvolvida para o primeiro par de questões do efeito certeza.

Tabela 2: Efeito Certeza - Par 1

\begin{tabular}{|c|c|c|c|c|c|c|c|c|c|c|c|c|}
\hline & \multirow[t]{2}{*}{ QUESTÃo } & \multirow[t]{2}{*}{ PROSPECTO } & \multirow[t]{2}{*}{ GERAL } & \multicolumn{2}{|c|}{ GÊNERO } & \multicolumn{3}{|c|}{ PERFIL } & \multicolumn{4}{|c|}{ PERÍODO DA GRADUAÇÃO } \\
\hline & & & & MASC. & FEM. & CONS. & MOD. & ARROJ. & 1 & 2 & 3 & 4 \\
\hline \multirow{4}{*}{ PAR 1} & Q1 & A: $(\$ 4000: 80 \% ; \$ 0: 20 \%)$ & 30.9 & 36.1 & 25.8 & 25.2 & 32.3 & 47.8 & 30.4 & 39.7 & 32.9 & 30.3 \\
\hline & $N: 369$ & B: $(\$ 3000: 100 \%)$ & $69,1^{* *}$ & $63,9 *$ & $74,2 *$ & 74.8 & 67.7 & 52.2 & 69.6 & 60.3 & 67.1 & 69.7 \\
\hline & Q2 & A: $(\$ 4000: 20 \% ; \$ 0: 80 \%)$ & 41 & 47.8 & 34.2 & 35 & 42.7 & 56.5 & 40.2 & 49.2 & 39.1 & 40.8 \\
\hline & $N: 366$ & B: $(\$ 3000: 25 \% ; \$ 0: 75 \%)$ & $59 * *$ & $52,2 *$ & $65,8^{*}$ & 65 & 57.3 & 43.5 & 59.8 & 50.8 & 60.9 & 59.2 \\
\hline
\end{tabular}

(*): Significância estatística ao nível de 0,$05 ;(* *)$ : Significância estatística ao nível de 0,01 ; Fonte: Elaborado pelos autores (2018). 
No Par 1, em termos gerais, nota-se que o efeito certeza foi respeitado em ambos as questões, de maneira que o prospecto B foi preferível ao A nas duas opções. Isso pode ser explicado em virtude de a amostra preferir as alternativas com maiores probabilidades de se obter ganho, sem dar ênfase para as opções com retornos mais significativos. O mesmo não foi verificado nos estudos de Kahneman e Tversky (1979), Kimura, Basso e Krauter (2003) e Rogers et al., (2007), onde o efeito certeza foi violado quando A foi preferível a B na questão 2 .

Deste Par analisado, constata-se que o público feminino (Q1:74,2\%; Q2:65,8\%) apresentou comportamento mais avesso ao risco para ganhos quando comparado aos homens. Ao ser verificado o posicionamento frente a investimentos, o que predominou foi o perfil conservador (Q1:74,8\%; Q2:65\%) seguido pelo moderado. Com relação aos quartis, não foi verificado diferença dos anos de estudo nas decisões dos indivíduos, o que seguiu na mesma linha dos resultados encontrados por Marinho et al., (2009). A Tabela 3 contém os resultados para o segundo grupo de questões analisados para o efeito certeza.

Tabela 3: Efeito Certeza - Par 2

\begin{tabular}{|c|c|c|c|c|c|c|c|c|c|c|c|c|}
\hline & \multirow[t]{2}{*}{ QUESTÃo } & \multirow[t]{2}{*}{ PROSPECTO } & \multirow[t]{2}{*}{ GERAL } & \multicolumn{2}{|c|}{ GÊNERO } & \multicolumn{3}{|c|}{ PERFIL } & \multicolumn{4}{|c|}{$\begin{array}{l}\text { PERÍODO DA } \\
\text { GRADUAÇÃO }\end{array}$} \\
\hline & & & & MASC. & FEM. & CONS. & MOD. & ARROJ. & 1 & 2 & 3 & 4 \\
\hline & Q3 & $\begin{array}{c}\text { A: (Viagem de três } \\
\text { semanas para a Inglaterra, } \\
\text { França e Itália: } 50 \% \text {; } \\
\text { Nada: } 50 \%)\end{array}$ & 23,2 & 26,6 & 19,9 & 23,2 & 22,5 & 30,4 & 22,8 & 30,2 & 20 & 19,7 \\
\hline \multirow{4}{*}{ PAR 2} & & $\begin{array}{c}\text { B: (Viagem de uma } \\
\text { semana para a Inglaterra: }\end{array}$ & & & & & & & & & & \\
\hline & $N: 370$ & $\begin{array}{c}100 \%) \\
\text { A: (Viagem de três } \\
\text { semanas para a Inglaterra, } \\
\text { França e Itália: } 5 \% \text {; Nada: }\end{array}$ & $76,8 * *$ & 73,4 & 80,1 & 76,8 & 77,5 & 69,6 & 77,2 & 69,8 & 80 & 80,3 \\
\hline & Q4 & $\begin{array}{c}95 \%) \\
\text { B: (Viagem de uma } \\
\text { semana para a Inglaterra: }\end{array}$ & 35,1 & 41 & 29,3 & 30,9 & 36,2 & 47,8 & 37,3 & 41,9 & 27,1 & 33,3 \\
\hline & $N: 367$ & 10\%; Nada: $90 \%$ ) & $64,9 * *$ & $59 *$ & $70,7 *$ & 69,1 & 63,8 & 52,2 & 62,7 & 58,1 & 72,9 & 66,7 \\
\hline
\end{tabular}

(*): Significância estatística ao nível de 0,$05 ;(* *)$ : Significância estatística ao nível de 0,01 ;

Fonte: Elaborado pelos autores (2018).

Neste Par, também houve o respeito ao efeito certeza em ambas situações que foram expostas, onde o prospecto $\mathrm{B}$ foi a escolha da maioria frente à alternativa $\mathrm{A}$; de modo que os respondentes optaram pelo percentual de retorno, posicionando-se de maneira avessa ao risco. Esses resultados contrapõem os trabalhos de Kahneman e Tversky (1979) e Rogers et al. (2007) que em suas análises, a amostra violou o efeito certeza na questão 4, quando A foi preferível a B.

Quando segmentada a amostra por categorias de análise, percebe-se que gênero e perfil apresentaram o comportamento esperado. $\mathrm{O}$ maior percentual nos prospectos que 
envolviam menor risco foi representado pelo público feminino (Q3:80,1\%; Q4:70,7\%) e pelo perfil conservador (Q3:76,8\%; Q4:69,1\%) seguido do moderado. Contudo, em relação aos anos de estudo, percebe-se que na questão 3 os últimos anos da graduação tiveram maior peso na decisão, seguindo assim de maneira contrária ao estudo de Marinho et al., (2009). Estes mostraram que este tipo de variável não interfere no posicionamento dos indivíduos. Referente à segunda questão analisada, os anos de estudo não mostraram significância.

Embora as questões do Par 2 apresentavam apenas prospectos que envolviam decisões relacionadas a viagens, o comportamento da amostra foi muito próximo ao evidenciado no Par 1. Apenas os resultados para período da graduação que se mostraram mais expressivos em escolhas envolvendo risco com decisões não financeiras, ainda que não possam ser considerados estatisticamente significativos. A Tabela 4 apresenta os resultados do terceiro par de análise.

No último Par analisado referente o efeito certeza, houve uma divisão da amostra de maneira que o efeito certeza foi violado, uma vez que a amostra optou pelo valor do prospecto em vez do percentual, posicionando-se a favor do risco. Na questão 5 a amostra respeitou o efeito, onde a decisão foi em favor da probabilidade ao invés do valor, sendo neste caso B preferível a A. Já na questão 6, os indivíduos optaram pela alternativa A quando comparado com B, justificando-se em função do percentual de retorno possuir pouca diferença, o que faz com que optem por probabilidades de ganhos maiores. Os mesmos resultados analisados neste Par, convergiram para os encontrados por Kahneman e Tversky (1979), Kimura, Basso e Krauter (2003) e Rogers et al., (2007).

Tabela 4: Efeito Certeza - Par 3

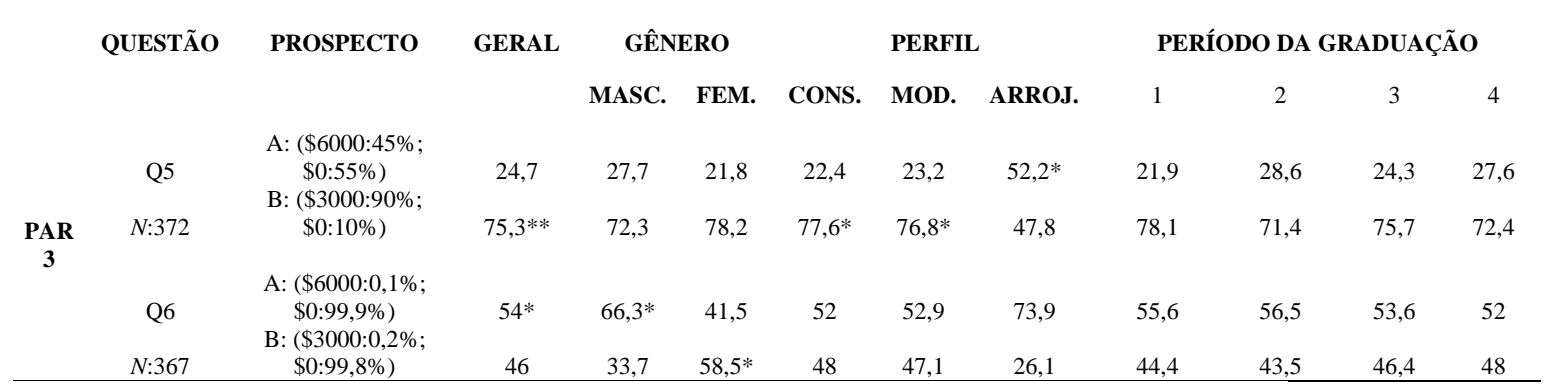

(*): Significância estatística ao nível de 0,$05 ;(* *)$ : Significância estatística ao nível de 0,01 ;

Fonte: Elaborado pelos autores (2018).

Na questão 5 os demais grupos de questões seguiram os padrões estabelecidos com predominância do público feminino $(78,2 \%)$ e perfis conservador $(77,6 \%)$ seguido do moderado, para posicionamento avesso ao risco. Com relação aos anos de estudos, estes não 
mostraram significância estatística tanto a 99\% quanto a 95\%. Ao ser analisada a questão 6 , ocorreu uma inversão de valores, de modo que os resultados foram representados pelo público masculino $(66,3 \%)$ e perfil arrojado $(73,9 \%)$, por se tratarem de uma escolha propensa ao risco. Com relação aos anos de estudos, estes mantiveram-se constantes, sem interferir nos resultados.

De um modo geral, o efeito certeza se mostrou importante para a análise, permitindo o estabelecimento de alguns padrões de respostas que foram verificados no decorrer das questões. Nos pares analisados, foi possível constatar o respeito aos pressupostos do efeito, de maneira que nestas questões a maior parte dos indivíduos optaram pelos prospectos com a probabilidade maior de ganho, sendo representados por B preferível a A. Frente a este posicionamento avesso ao risco, o gênero foi representado pelo público feminino, enquanto o perfil pelo conservador, seguido do moderado. Os anos de estudos não mostraram significância estatística, deste modo não interferindo nos resultados.

Ao levar em consideração os resultados do terceiro par, o qual violou o efeito certeza, notou-se que os indivíduos optaram na questão 6 pelo valor do prospecto, antes da probabilidade do ganho. Nesta situação a favor do risco, percebe-se que relacionado ao gênero, os homens exerceram maior influência nas respostas, e referente ao perfil o arrojado teve maior representatividade nos prospectos. Contudo, observa-se que os anos de estudos permaneceram sem significância nos resultados, levando a crer que o desenvolvimento ao longo da graduação não interfere, na percepção sobre o risco por parte dos indivíduos da amostra.

As próximas análises são referentes ao efeito reflexão, e a metodologia utilizada para a descrição dos resultados é a mesma que foi utilizada para o efeito certeza. Com comparações realizadas em pares de questões, levando em conta toda a segmentação de variáveis.

\subsection{Efeito reflexão}

Ao considerarmos o efeito reflexão, os agentes tendem a ser avessos ao risco quando estão diante de possibilidades de ganho, e tendem a ser tomadores de risco quando as mesmas possibilidades envolvem risco (ROGERS et al., 2007). A tabela 5 contém os resultados para o primeiro par do efeito reflexão. 
Tabela 5: Efeito Reflexão - Par 1

\begin{tabular}{|c|c|c|c|c|c|c|c|c|c|c|c|c|}
\hline & \multirow[t]{2}{*}{ QUESTÃO } & \multirow[t]{2}{*}{ PROSPECTO } & \multirow[t]{2}{*}{ GERAL } & \multicolumn{2}{|c|}{ GÊNERO } & \multicolumn{3}{|c|}{ PERFIL } & \multicolumn{4}{|c|}{ PERÍODO DA GRADUAÇÃO } \\
\hline & & & & MASC. & FEM. & CONS. & MOD. & ARROJ. & 1 & 2 & 3 & 4 \\
\hline \multirow{4}{*}{ PAR 1} & Q1 & 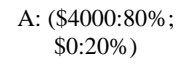 & 30,9 & 36,1 & 25,8 & 25,2 & 32,3 & 47,8 & 30,4 & 39,7 & 32,9 & 30,3 \\
\hline & $N: 369$ & B: $(\$ 3000: 100 \%)$ & $69,1 * *$ & $63,9 *$ & $74,2 *$ & 74,8 & 67,7 & 52,2 & 69,6 & 60,3 & 67,1 & 69,7 \\
\hline & Q7 & $\begin{array}{c}\text { A: }(-\$ 4000: 80 \% \\
\$ 0: 20 \%)\end{array}$ & $74,9 * *$ & 75,1 & 74,7 & $68,8^{*}$ & $76,2^{*}$ & $95,7^{*}$ & 76,6 & 79,4 & 72,5 & 71,1 \\
\hline & $N: 371$ & B: $(-\$ 3000: 100 \%)$ & 25,1 & 24,9 & 25,3 & 31,2 & 23,8 & 4,3 & 23,4 & 20,6 & 27,5 & 28,9 \\
\hline
\end{tabular}

(*): Significância estatística ao nível de 0,$05 ;(* *)$ : Significância estatística ao nível de 0,01 ;

Fonte: Elaborado pelos autores (2018).

Nesta seção, examinaram-se as probabilidades que envolvem perdas, diferentemente da anterior, onde discutiu-se apenas as preferências entre perspectivas positivas. Para isso, em cada Par analisado, na primeira questão foram expostos prospectos com percentuais de ganho; enquanto, na segunda apresentaram os prospectos com percentuais similares aos da primeira questão, sendo estes referentes às perdas. O que se espera para este efeito é que na primeira questão do Par, os indivíduos se posicionem de modo avesso ao risco; enquanto. na segunda se posicionem a favor.

$\mathrm{Na}$ questão 1, os respondentes optaram pelo prospecto de maior probabilidade de ganho $(69,1 \%)$. Já na questão 7 , os indivíduos se posicionam a favor do risco frente às probabilidades de perdas $(74,9 \%)$. Com esses resultados, foi possível notar o respeito ao efeito reflexão, com resultados similares nos trabalhos de Kahneman e Tversky (1979), Basso, Kimura e Krauter (2003) e Rogers et al., (2007).

Com relação ao gênero, percebe-se que tanto homens quanto mulheres são avessos ao risco em prospectos que envolvem ganhos e propensos ao risco em prospectos que envolvem perdas. Contudo, a questão 7 não se mostrou estatisticamente significativa aos níveis analisados quando comparada ao gênero. Neste Par, os resultados para perfil de investimento além de indicarem significância estatística foram expressivos e convergiram com a literatura, resultados estes similares aos encontrados por Cavallaro et al. (2015). Em ambas as questões, os perfis se comportaram como prevê o efeito reflexão na questão 1; no entanto, o perfil arrojado $(52,2 \%)$ demonstrou maior preferência pela certeza, quando poderia se esperar uma maior propensão ao risco. Já na questão7, a escolha do perfil arrojado $(95,7 \%)$ foi massiva na incerteza da perda. Quanto ao perfil conservador, a maioria dos respondentes $(68,8 \%)$ também preferiram correr o risco de perder mais, do que a certeza de perder um valor menor. Sobre o perfil moderado, este manteve-se, em ambas as questões do Par 1, com percentuais intermediários entre os perfis conservador e arrojado. 
Por fim, para o período da graduação não houve nenhum quartil com diferenças significativas nas escolhas entre os prospectos, seguindo a mesma linha dos resultados de Marinho et al., (2009). A tabela 6 traz os resultados para o segundo par do efeito reflexão.

Tabela 6: Efeito Reflexão - Par 2

\begin{tabular}{|c|c|c|c|c|c|c|c|c|c|c|c|c|}
\hline \multirow{2}{*}{\multicolumn{2}{|c|}{ QUESTÃo }} & \multirow{2}{*}{ PROSPECTO } & \multirow{2}{*}{ GERAL } & \multicolumn{2}{|c|}{ GÊNERO } & \multicolumn{3}{|c|}{ PERFIL } & \multicolumn{4}{|c|}{ PERÍODO DA GRADUAÇÃO } \\
\hline & & & & MASC. & FEM. & CONS. & MOD. & ARROJ. & 1 & 2 & 3 & 4 \\
\hline \multirow{4}{*}{ PAR 2} & Q2 & A: $(\$ 4000: 20 \% ; \$ 0: 80 \%)$ & 41 & 47,8 & 34,2 & 35 & 42,7 & 56,5 & 40,2 & 49,2 & 39,1 & 40,8 \\
\hline & $N: 366$ & B: $(\$ 3000: 25 \% ; \$ 0: 75 \%)$ & $59 * *$ & $52,2^{*}$ & $65,8^{*}$ & 65 & 57,3 & 43,5 & 59,8 & 50,8 & 60,9 & 59,2 \\
\hline & Q8 & A: $(-\$ 4000: 20 \% ; \$ 0: 80 \%)$ & $54,2 *$ & 54,9 & 53,5 & 46,8 & 58,1 & 56,5 & 58,4 & 62,5 & 55,1 & 46,7 \\
\hline & $N: 317$ & B: $(-\$ 3000: 25 \% ; \$ 0: 75 \%)$ & 45,8 & 45,1 & 46,5 & 53,2 & 41,9 & 43,5 & 41,6 & 37,5 & 44,9 & 53,3 \\
\hline
\end{tabular}

(*): Significância estatística ao nível de 0,$05 ;(* *)$ : Significância estatística ao nível de 0,01 ; Fonte: Elaborado pelos autores (2018).

Conforme a tabela 6 , também se observou o cumprimento do efeito reflexão nos resultados gerais, de maneira que na questão 2 , os indivíduos escolheram o percentual de retorno; enquanto, na questão 8 o posicionamento foi a favor do risco, isso pode ser representado por $(\mathrm{Q} 2: 52,2 \%$; Q8:54,2\%) respectivamente. Contudo, a diferença entre as escolhas não foi tão expressiva quanto no primeiro par analisado deste efeito. Da mesma forma que a aversão ao risco no efeito certeza viola o princípio da teoria da utilidade esperada, o mesmo ocorre com a propensão ao risco no efeito reflexão.

Ao analisar as demais variáveis, na questão 2 o gênero foi representado pelo feminino $(65,8 \%)$; enquanto, na questão 8 pelo masculino $(54,9 \%)$, embora com resultados próximos do público feminino. Quando analisados os perfis, percebe-se que os estudantes que se consideram conservadores adotaram um comportamento distinto da média amostral na questão 8, apontando uma preferência pela certeza de perda, contudo o posicionamento arrojado se manteve à frente dos demais. Esse resultado é condizente com a teoria da utilidade esperada e contrário ao efeito reflexão. Embora não tenha apresentado significância estatística aos níveis estabelecidos pela pesquisa, é importante notar que esse resultado é oposto ao apresentado no Par 1 e pode indicar que a perda é possível e não certa, e que indivíduos mais conservadores optam pela opção que geraria menor prejuízo.

Com relação aos anos de estudo, notou-se opiniões próximas em todos os quartis na primeira questão, não havendo oscilações significativas entre as escolhas, e apenas um declínio relativo do primeiro ao último quartil. E, na segunda questão, os anos iniciais mostraram-se um pouco mais propensos ao risco do que os últimos, porém sem significância 
estatística. Esses resultados condizem com os obtidos por Oliveira e Krauter (2015). A seguir, na Tabela 7 tem-se os resultados para o terceiro par de análise do efeito reflexão.

Tabela 7: Efeito Reflexão - Par 3

\begin{tabular}{|c|c|c|c|c|c|c|c|c|c|c|c|c|}
\hline & \multirow[t]{2}{*}{ QUESTÃO } & \multirow[t]{2}{*}{ PROSPECTO } & \multirow[t]{2}{*}{ GERAL } & \multicolumn{2}{|c|}{ GÊNERO } & \multicolumn{3}{|c|}{ PERFIL } & \multicolumn{4}{|c|}{ PERÍODO DA GRADUAÇÃO } \\
\hline & & & & MASC. & FEM. & CONS. & MOD. & ARROJ. & 1 & 2 & 3 & 4 \\
\hline & Q5 & A: $(\$ 6000: 45 \% ; \$ 0: 55 \%)$ & 24,7 & 27,7 & 21,8 & 22,4 & 23,2 & $52,2 *$ & 21,9 & 28,6 & 24,3 & 27,6 \\
\hline \multirow[t]{3}{*}{ PAR 3} & $N: 372$ & B: (\$3000:90\%; \$0:10\%) & $75,3 * *$ & 72,3 & 78,2 & $77,6^{*}$ & $76,8^{*}$ & 47,8 & 78,1 & 71,4 & 75,7 & 72,4 \\
\hline & Q9 & A: $(-\$ 6000: 45 \% ; \$ 0: 55 \%$ & $64,8^{* *}$ & 68,5 & 61,5 & 68,3 & 62,3 & 69,6 & 67,9 & 66,7 & 69,1 & 56,6 \\
\hline & $N: 369$ & B: $(-\$ 3000: 90 \% ; \$ 0: 10 \%)$ & 35,2 & 31,5 & 38,8 & 31,7 & 37,7 & 30,4 & 32,1 & 33,3 & 30,9 & 43,4 \\
\hline
\end{tabular}

(*): Significância estatística ao nível de 0,$05 ;(* *)$ : Significância estatística ao nível de 0,01 ;

Fonte: Elaborado pelos autores (2018).

Os resultados deste Par, seguiram no mesmo padrão que os dois primeiros, de modo que se respeitou o efeito reflexão, com preferência na questão 5 pela certeza de ganho; enquanto, na questão 9 pela propensão ao risco (Q5:75,3\% Q9:64,8\%), resultados estes com significância estatística. Frente a este posicionamento, o gênero seguiu a mesma categorização vista até então, representados pelo feminino e masculino, respectivamente, para cada uma das questões do Par (Q5:78,2\%; Q9:68,5\%), embora os resultados não mostraram significância estatística.

Ao analisar o perfil, na primeira questão o mais escolhido foi o conservador seguido pelo moderado por representarem menor risco, caracterizados por $(77,6 \%)$ e $(76,8 \%)$ respectivamente. $\mathrm{Na}$ segunda questão, os perfis se mantiveram próximos, com pouca variação entre si, porém com o arrojado na frente dos demais $(69,6 \%)$. Cabe destacar que as escolhas de cada um dos perfis se mostraram estatisticamente significativa, portanto, permitindo inferir que há diferenças significativas nas escolhas em função do perfil de investimento dos estudantes

Os anos de estudo para este Par analisado não expressaram grandes desigualdades, deste modo não interferindo nos resultados verificados. A Tabela 8 contém o posicionamento dos estudantes, quando os prospectos apresentam percentuais muito próximos, tanto no campo positivo quanto negativo. 
Tabela 8: Efeito Reflexão - Par 4

\begin{tabular}{|c|c|c|c|c|c|c|c|c|c|c|c|c|}
\hline & \multirow[t]{2}{*}{ QUESTÃO } & \multirow[t]{2}{*}{ PROSPECTO } & \multirow[t]{2}{*}{ GERAL } & \multicolumn{2}{|c|}{ GÊNERO } & \multicolumn{3}{|c|}{ PERFIL } & \multicolumn{4}{|c|}{$\begin{array}{l}\text { PERÍODO DA } \\
\text { GRADUAÇÃO }\end{array}$} \\
\hline & & & & MASC. & FEM. & CONS. & MOD. & ARROJ. & 1 & 2 & 3 & 4 \\
\hline \multirow{3}{*}{ PAR 4} & Q6 & A: $(\$ 6000: 0,1 \% ; \$ 0: 99,9 \%)$ & $54 *$ & $66,3^{*}$ & 41,5 & 52 & 52,9 & 73,9 & 55,6 & 56,5 & 53,6 & 52 \\
\hline & $N: 367$ & B: $(\$ 3000: 0,2 \% ; \$ 0: 99,8 \%)$ & 46 & 33,7 & $58,5^{*}$ & 48 & 47,1 & 26,1 & 44,4 & 43,5 & 46,4 & 48 \\
\hline & $\begin{array}{c}\text { Q10 } \\
N: 372\end{array}$ & $\begin{array}{l}\text { A: }(-\$ 6000: 0,1 \% ; \$ 0: 99,9 \%) \\
\text { B: }(-\$ 3000: 0,2 \% ; \$ 0: 99,8 \%)\end{array}$ & $\begin{array}{c}50,5^{*} \\
49,5\end{array}$ & $\begin{array}{c}56,8^{*} \\
43,2\end{array}$ & $\begin{array}{c}44,4 \\
55,6^{*}\end{array}$ & $\begin{array}{l}45,2 \\
54,8\end{array}$ & $\begin{array}{l}52,9 \\
47,1\end{array}$ & $\begin{array}{l}56,5 \\
43,5\end{array}$ & $\begin{array}{l}57,7 \\
42,3\end{array}$ & $\begin{array}{l}51,6 \\
48,4\end{array}$ & $\begin{array}{l}50,7 \\
49,3\end{array}$ & $\begin{array}{l}38,2 \\
61,8\end{array}$ \\
\hline
\end{tabular}

(*): Significância estatística ao nível de 0,05 ; (**): Significância estatística ao nível de 0,01;

Fonte: Elaborado pelos autores (2018).

No último Par analisado no efeito reflexão, os prospectos disponíveis para escolha da amostra estão apresentados de maneira distinta dos anteriores. Na primeira questão, as chances de ganho foram reduzidas e o risco de não ganhar nada foi avantajado, porém, aceitando o risco, o valor a ser ganho foi dobrado. Na segunda questão, a diferença está no sinal negativo, ou seja, ao invés de ganho ocorreram perdas. Os resultados gerais indicam que os indivíduos se arriscaram mais na questão 6 e optaram pelo prospecto A (54\%) ao invés do B (46\%), onde o valor de retorno era maior, embora a probabilidade de ganho fosse pequena, violando deste modo o efeito reflexão, e o padrão observados nas questões anteriores. Já para a questão 10, o resultado geral mostrou diferença nas escolhas, onde $(50,5 \%)$ optaram pelo prospecto $\mathrm{A}$ e $(49,5 \%)$ pelo $\mathrm{B}$, respeitando o posicionamento que foi visto até então para a segunda questão dos pares apresentados no efeito reflexão. Essa propensão ao risco por parte das duas questões do par, justifica-se devido ao fato dos prospectos possuírem pouca diferença percentual.

Com relação ao demais variáveis, o gênero teve maior influência com o público masculino expressados por (Q6:66,3\%; Q10:56,8\%). Devido ao posicionamento a favor do risco, o perfil arrojado teve maior representatividade nos resultados perante os demais (Q6:73,9\%; Q10:56,5\%). Em ambos os prospectos escolhidos, percebeu-se que os anos iniciais da graduação se mantiveram propensos ao risco, embora não possuindo significância estatística.

Assim como no trabalho de Kahneman e Tversky (1979), o efeito reflexão foi uma importante ferramenta para auxiliar a compreensão das escolhas da amostra. Ao longo dos resultados observados, constatou-se o respeito ao efeito na maioria dos pares analisados. Com os resultados obtidos, pode notar que os indivíduos são avessos ao risco em prospectos de ganhos, e propensos em situações de perdas, devido a esta opção ter uma probabilidade de reduzir a perda em uma situação hipotética. Os demais grupos analisados, seguiram os resultados vistos no primeiro efeito e ao mesmo tempo esperado, com predominância do 
público feminino e perfil conservador em prospectos com maiores possibilidades de ganhos, e público masculino e perfil arrojado em situações propensas ao risco. A próxima análise, contém os resultados para o efeito isolamento, onde são expostas situações de maior complexidade, exigindo maior reflexão por parte dos respondentes.

\subsection{Efeito Isolamento}

De acordo com Rogers et al., (2007), o efeito isolamento foi o elemento chave utilizado por Kahneman e Tversky para o desenvolvimento da Teoria do Prospecto. Por meio dele, observou-se que os agentes geralmente descartam componentes que são compartilhados pelas probabilidades em consideração, e centralizam sua análise sobre os componentes que distinguem as opções de escolha, numa forma de simplificar o processo de tomada de decisão (MACEDO JUNIOR, 2003).

Foram expostas situações mais complexas do que as apresentadas nos outros efeitos, exigindo deste modo, maior reflexão e analise dos possíveis resultados. O Case 3, expôs a seguinte problemática: além dos recursos que você possui, você recebeu mais \$1000. Agora, você deve escolher entre as alternativas abaixo.

Este efeito é muito complexo e demanda maior atenção para sua interpretação. Nele os indivíduos antes de optarem entre os prospectos, já iniciam o problema obtendo uma "bonificação", de modo que com a qual, espera-se que os respondentes optem por reduzir o risco para ganhos, sendo assim avessos ao risco para tal situação e propensos para situações de perdas, uma vez que esta possui uma oportunidade de reduzir a perca.

A análise realizada pelo efeito isolamento tende a ser similar ao efeito reflexão onde os indivíduos se posicionam em favor da maior probabilidade de obter ganho e da menor de ter uma perda, indiferente do valor. Neste par analisado, a amostra respeitou o efeito isolamento, onde na primeira questão $\mathrm{B}$ foi preferível a $\mathrm{A}$; enquanto, na segunda $\mathrm{O}$ posicionamento foi o inverso com A preferível a B (Case3:62,2\%; Case3.1:60,1\%) sendo evidenciado resultados parecidos nos estudos de Kahneman e Tversky (1979), Kimura, Basso e Krauter (2003) e Rogers et al., (2007).

\begin{tabular}{c|c} 
Alternativa A & Alternativa B \\
\hline $50 \%$ de chances de ganhar $\$ 1000$ & $100 \%$ de chances de ganhar $\$ 500$ \\
$50 \%$ de chances de ganhar $\$ 0$ & \\
\hline
\end{tabular}


Do mesmo modo, o Case 3.1, levantou a seguinte situação: além dos recursos que você possui, você recebeu mais \$2000. Agora, você deve escolher entre as alternativas a seguir:

\begin{tabular}{l|l} 
Alternativa A & Alternativa B \\
\hline $50 \%$ de chances de perder $\$ 1000$ & $100 \%$ de chances de perder $\$ 500$ \\
$50 \%$ de chances de perder $\$ 0$ & \\
\hline
\end{tabular}

Os resultados dos dois cases são apresentados na Tabela 9, a mesma contempla o único par do efeito isolamento.

Tabela 9: Efeito Isolamento - Par1

\begin{tabular}{|c|c|c|c|c|c|c|c|c|c|c|c|c|}
\hline & \multirow[t]{2}{*}{ QUESTÃO } & \multirow[t]{2}{*}{ PROSPECTO } & \multirow[t]{2}{*}{ GERAL } & \multicolumn{2}{|c|}{ GÊNERO } & \multicolumn{3}{|c|}{ PERFIL } & \multicolumn{4}{|c|}{$\begin{array}{l}\text { PERÍODO DA } \\
\text { GRADUACCÃO }\end{array}$} \\
\hline & & & & MASC. & FEM. & CONS. & MOD. & ARROJ. & 1 & 2 & 3 & 4 \\
\hline \multirow{4}{*}{ PAR 1} & CASE 3 & A: $(\$ 1000: 50 \% ; \$ 0: 50 \%)$ & 37,8 & 45 & 30,8 & 24,2 & 43,1 & $60,9 *$ & 36,8 & 44,4 & 42,6 & 28 \\
\hline & $N: 365$ & B: $(\$ 500: 100 \%)$ & $62,2 * *$ & $55^{*}$ & $69,2 *$ & $75,8^{*}$ & $56,9^{*}$ & 39,1 & 63,2 & 55,6 & 57,4 & 72 \\
\hline & CASE 3.1 & A: $(-\$ 1000: 50 \% ; \$ 0: 50 \%)$ & $60,1 * *$ & $69,5^{*}$ & $51,1^{*}$ & $50^{*}$ & $63,4^{*}$ & $82,6^{*}$ & 66,4 & 63,3 & 52,2 & 56,8 \\
\hline & $N: 361$ & B: $(-\$ 500: 100 \%)$ & 39,9 & 30,5 & 48,9 & $50 *$ & 36,6 & 17,4 & 33,6 & 36,7 & 47,8 & 43,2 \\
\hline
\end{tabular}

(*): Significância estatística ao nível de 0,$05 ;(* *)$ : Significância estatística ao nível de 0,01 ;

Fonte: Elaborado pelos autores (2018).

Com relação aos demais grupos da pesquisa, no Case 3, verificou-se que o padrão foi mantido onde se estabeleceu o público feminino $(69,2 \%)$, seguido do perfil conservador $(75,8 \%)$. Ao analisar os anos de estudo, notou-se que os anos finais da graduação, tiveram mais influência, contudo sem possuir significância estatística. No Case 3.1 onde a amostra se posicionou em prol do risco para reduzir o potencial de perda, o padrão de posicionamento foi mantido com força do público masculino $(69,5 \%)$ e do perfil arrojado $(82,6 \%)$ sem interferência dos anos de estudos, nos resultados.

Com os resultados apurados, foi possível notar o respeito ao que era esperado para o efeito isolamento, e aos padrões de respostas vistos até então. Antes de escolherem entre os prospectos, os indivíduos já ganhavam uma bonificação hipotética, e de acordo com o efeito, espera-se que eles não levem em consideração este bônus e se posicionem de maneira avessa ao risco para escolhas envolvendo o percentual, e de maneira propensa em situações de perda. Como essa identidade foi mantida, conclui-se que o efeito isolamento é um importante fator na composição das escolhas. As demais categorias analisadas neste par, seguiram o mesmo padrão de respostas dos demais efeitos, destacando-se o gênero feminino e o perfil conservador para escolhas relacionadas a probabilidade, e o gênero masculino e perfil 
arrojado para escolhas propensas ao risco, ambas situações sem sofrerem a interferência dos anos de estudos.

\section{Considerações finais}

As decisões dos agentes econômicos frentes a situações conflitantes envolvendo risco pode ser melhor compreendida com o estudo da teoria do prospecto, a qual pressupõe que os indivíduos tomam suas decisões dotados de racionalidade limitada. Este trabalho analisou o posicionamento de acadêmicos dos cursos de Administração, Ciências Contábeis e Ciências Econômicas sobre a ótica dos efeitos certeza, reflexão e isolamento. Assim como, realizado no trabalho dos predecessores desta teoria, e indo além, verificou como diferentes grupos poderiam reagir nas escolhas.

Embora cada efeito proponha uma interpretação distinta dos resultados, todos eles interligam-se de maneira que o padrão de respostas verificadas em um, acabam sendo esperadas nos demais. Com a análise desenvolvida, constatou-se que a teoria comportamental pode ser utilizada para interpretar os resultados e auxiliar na compreensão das escolhas dos agentes.

No efeito certeza, os indivíduos foram expostos a duas situações de ganhos, diferenciadas com relação ao percentual de cada. De acordo com os pressupostos do efeito, se esperou que os respondentes optassem pelos prospectos de maior probabilidade de ganho, agindo de modo avesso ao risco. Como isso foi respeitado, pode se determinar que o efeito deve ser utilizado como parâmetro para a explicação das escolhas. Resultados similares foram encontrados nos estudos de Kahneman e Tversky (1979) e Oliveira e Krauter (2015).

O segundo efeito analisado foi o de reflexão, neste o indivíduo tinha duas opções para escolha, sendo a primeira referente a possibilidades de ganho, e a segunda envolvendo probabilidades de perda. De acordo com este efeito, os respondentes deveriam se posicionar primeiramente a favor da maior possibilidade de ganho, para posteriormente se posicionar de maneira propensa ao risco, uma vez que esta opção envolvia prospectos de perda. Os resultados encontrados respeitaram o efeito, podendo este também ser utilizado para auxiliar a compreensão das escolhas sobre risco.

A última análise foi realizada com o efeito isolamento, nesta seção antes dos indivíduos fazerem a escolha, eles ganhavam uma bonificação para posteriormente se posicionarem. Neste efeito, foram expostas duas possibilidades, sendo a primeira referente 
a ganho e a segunda concernente a perda. Uma vez que eles dispunham da bonificação e sabendo que a utilidade esperada entre os prospectos é a mesma, espera-se que os indivíduos isolem o que já possuem e optem por escolhas avessas ao risco, em situações de ganho e propensas em situações de perdas. Com os resultados, observou-se o respeito ao efeito, e deste modo a teoria do prospecto pode ser utilizada por completo como um fator condicionante das escolhas.

Ao analisar as variáveis gênero, perfil e anos de estudo, foi possível estabelecer um padrão de respostas para diferentes percepções de risco, as quais foram mantidas no decorrer de toda análise. Nas respostas que foram avessas ao risco em favor do percentual de retorno, foi possível notar que o gênero feminino, e os perfis conservador e moderado, predominaram nos resultados. Em contrapartida, em respostas propensas ao risco para que fossem minimizadas as probabilidades de perdas, houve a predominância do gênero masculino e o perfil arrojado nas respostas. No entanto ao analisar os anos de estudo, foi possível notar que estes divergiram pouco no decorrer dos quartis, e ainda, a familiaridade com o mercado financeiro não impactou significativamente nas escolhas dos indivíduos. Vale ressaltar que o gênero e o perfil apresentaram significância estatística para alguns resultados, enquanto a variável anos de estudos não se mostrou significante aos níveis estabelecidos de $0,01^{*} \mathrm{e}$ $0,05 * *$.

Com os resultados obtidos e levando em consideração os objetivos do estudo, foi possível ressaltar que a teoria da Finança Comportamental pode ser utilizada para interpretar o posicionamento dos indivíduos frente situações de risco no mercado financeiro, assim como o gênero e o perfil. Esse posicionamento em prol da violação da utilidade esperada por parte dos indivíduos, pode ser explicado pela racionalidade limitada, que os mesmos possuem aliado as emoções e vieses cognitivos.

Como sugestão para futuros trabalhos, propomos a inserção de novas questões para melhor entender as características dos indivíduos como aspectos familiares, profissionais e culturais, a fim de intender e analisar qual o papel dessas variáveis nas escolhas sob a ótica de risco.

\section{REFERÊNCIAS}

ANACHE, M. C. A. Finanças comportamentais: uma avaliação crítica da moderna teoria de finanças. 2008. 148 f. Dissertação (Mestrado em Economia) - Programa de PósGraduação em Economia - Universidade Federal do Espírito Santo, Vitória, 2008. 
BARROS, T. S.; FELIPE, I. J. S. Teoria do prospecto: evidências aplicadas em finanças comportamentais. Revista de Administração Faces Jornal, v. 14, n. 4, p.86-105, out. 2015

BARBOSA, E. T.; BILK, A.; DA SILVA, T. P.; NAKAMURA, W. T. Aversão a perda e satisfação ao ganho nos aspectos comportamentais dos acadêmicos e profissionais da atuária. Caderno Profissional de Administração - UNIMEP Mestrado Profissional e Doutorado em Administração. 2017

BASSO, L. F. C.; KIMURA, H.; KRAUTER, E. Finanças comportamentais: investigação do comportamento decisório dos agentes brasileiros de acordo com a teoria do prospecto de Kahneman \& Tversky. Assembleia do Conselho Latino-Americano das Escolas de Administração, v. 38, 2003.

CAVALLARO, M.; PEREIRA JUNIOR, O.; SASSI, C. P.; CARVALHO, F. L. Impacto da renda, gênero, idade e área de formação na propensão ao risco financeiro. 2015 Disponível em: http://bibliotecadigital.fgv.br/dspace/bitstream/handle/10438/18870/GVcef_Cavallaro\%3b $\% 20$ Pereira $\% 20 \mathrm{Junior} \% 3 \mathrm{~b} \% 20 \mathrm{Sassi} \% 3 \mathrm{~b} \% 20 \mathrm{Carvalho}$.pdf? sequence $=1 \&$ isAllowed $=\mathrm{y}$.

Acesso em: 17 ago. 2018

FERREIRA, V. R. M. Psicologia econômica: mente, comportamento e escolhas. Guia de economia comportamental e experimental, São Paulo, v. 01, p. 165-175, 2015.

FRANCESCHINI, C. Introdução a finanças comportamentais. Guia de economia comportamental e experimental, São Paulo, v. 01, p. 176-188, 2015.

HALFELD, M.; TORRES, F. F. L. Finanças comportamentais: aplicações no contexto brasileiro. Revista de Administração de Empresas, São Paulo, v. 41, n. 02, p. 64-71, Abr./Jun. 2001.

HAUBERT, F. L. C.; DE LIMA, C. R. M.; DE LIMA, M. V. A. Finanças comportamentais: uma investigação com base na teoria do prospecto e no perfil do investidor de estudantes de cursos stricto sensu portugueses. Revista de Ciência da Administração. Florianópolis. v. 16, n. 38, abril-, 2014, p. 183-195. Universidade Federal de Santa Catarina. Santa Catarina.

HAUBERT, F. L. C.; LIMA, M. V. A.; HERLING, L. H. D. Finanças comportamentais: um estudo com base na teoria do prospecto e no perfil do investidor de estudantes de cursos stricto sensu da grande Florianópolis. Revista Estratégia \& Negócio. Florianópolis, v. 5, n.02, p. 171-199, Maio./Ago. 2012

KAHNEMAN, D.; TVERSKY, A. Prospect theory: an analysis of decision under risk. Econometrica, v. 47, n. 2, p. 263-291, Mar. 1979.

KAHNEMAN, D.; TVERSKY, A. The psychology of preferences. Scientific American, v. 146, p. 160-173, 1982.

KIMURA, H.; BASSO, L. F. C.; KRAUTER, E. Paradoxos em finanças: teoria moderna versus finanças comportamentais. Revista de Administração de Empresas, São Paulo, v. 46, n. 01, p.41-58, Jan/Mar. 2006. 
LENCINI, C. A. S.; ANDRADE, A. G. M. Finanças comportamentais: um estudo do perfil de investidores de agências bancárias do município de Porto Alegre/RS. Remas - Revista Metodista de Administração do Sul, Porto Alegre, v. 01, n. 01, p.01-21, 2016.

LIMA, M. V. Um estudo sobre finanças comportamentais. RAE - eletrônica, v. 02, n. 01, Jan./Jun. 2003. Disponível em: http://www.rae.com.br/eletronica/index.cfm?FuseAction=Artigo $\& I D=1873 \&$ Secao $=2^{\circ} \mathrm{PW}$ $\mathrm{C} \&$ Volume $=2 \&$ Numero $=1 \& A n o=2003$. Acesso em: 31 maio 2018.

MACEDO JUNIOR, J. S. Teoria do prospecto: uma investigação utilizando simulação de investimentos. 2003. 218 f. Tese (Doutorado) - Curso de Engenharia de Produção, UFSC, Florianópolis, 2003.

MARINHO, R. F.; LAGIOIA, U. C. T.; MACIEL, C. V; RODRIGUES, R. N. Finanças comportamentais: um estudo comparativo utilizando a teoria dos prospectos com os alunos de graduação do curso de ciências contábeis. Revista Brasileira de gestão de negócios, São Paulo, v. 11, n. 33, p. 383-403, out/dez, 2009.

MELO, C. L. L.; SILVA, C. A. T. Finanças comportamentais: um estudo da influência da faixa etária, gênero e ocupação na aversão à perda. RCO - Revista de Contabilidade e Organizações, São Paulo, v. 04, n. 08, p.03-23, jan/abril 2010.

MILANEZ, D. Y. Finanças comportamentais no Brasil. 2003. 53 f. Tese (Doutorado) Curso de Economia, Usp, São Paulo, 2003.

OLIVEIRA, L. R.; KRAUTER, E. Teoria do prospecto: como as finanças comportamentais podem explicar a tomada de decisão. Pretexto, Belo Horizonte, p.105-121, jul/set. 2015

PINDYCK, R.; RUBINFELD, D. L. Microeconomia. 7. ed. São Paulo: Makron Books, 2006.

READ, D. A ciência comportamental e a tomada de decisão pelo consumidor: algumas questões para os reguladores. Guia de Economia Comportamental e Experimental, São Paulo, p.128-135, 2015.

ROGERS, P.; SECURATO, J. R.; RIBEIRO, K. C. S. Finanças comportamentais no Brasil: um estudo comparativo. $I N$ : $7^{\circ}$ Congresso usp controladoria e contabilidade, 126, 2007. São Paulo: USP 2007.

SOARES, H. F. G.; BARBEDO, C. H. S. Desempenho acadêmico e a teoria do prospecto: estudo empírico sobre o comportamento decisório. RAC - Revista de Administração Contemporânea, Rio de Janeiro, p.64-82, Jan./Fev. 2013

THALER, R.; BARBERIS, N. A Survey of Behavioral Finance. In: CONSTANTINIDES, G.; HARRIS, M.; STULZ, R. (Eds.) Handbook of the Economics of Finance. New York: North-Holland, 2003.

VARIAN, H. R. Microeconomia: uma abordagem moderna. Rio de Janeiro: Elsevier, 2012. 
YOShINAGA, C. E.; OliVEIRA, R. F.; SIlveirA, A. D. M.; BARROS, L. A. B. C. Finanças comportamentais: uma introdução. Revista de Gestão, São Paulo, p.25-35, jul. 2008. Mensal. 